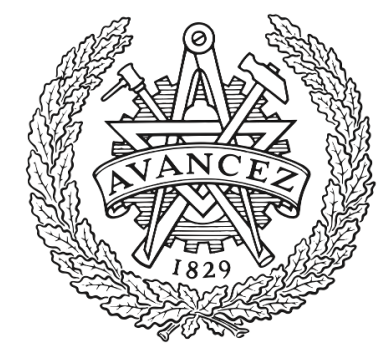

CHALMERS

UNIVERSITY OF TECHNOLOGY

\title{
Recycling Zinc from Metal Oxide Varistors Through Leaching and Cementation of Cobalt and Nickel
}

Downloaded from: https://research.chalmers.se, 2023-04-26 13:45 UTC

Citation for the original published paper (version of record):

Gutknecht, T., Colombus, Y., Steenari, B. (2017). Recycling Zinc from Metal Oxide Varistors

Through Leaching and Cementation of Cobalt and Nickel. Journal of Sustainable Metallurgy, 3(2):

239-250. http://dx.doi.org/10.1007/s40831-016-0072-6

N.B. When citing this work, cite the original published paper. 


\title{
Recycling Zinc from Metal Oxide Varistors Through Leaching and Cementation of Cobalt and Nickel
}

\author{
Toni Gutknecht ${ }^{1}(\mathbb{D}) \cdot$ Yuda Colombus $^{1} \cdot$ Britt-Marie Steenari $^{1}{ }^{\mathbb{B}}$
}

Published online: 8 August 2016

(c) The Author(s) 2016. This article is published with open access at Springerlink.com

\begin{abstract}
Metal oxide varistors (MOVs) are housed in a surge arrestor and composed of zinc oxide ( $>90 \mathrm{wt} \%)$ and other metal oxides such as antimony, bismuth, cobalt, manganese, and nickel. Due to the high concentration of zinc in MOVs, it is a better choice to recycle them as opposed to landfilling. This research set out to determine if cementation could be used as a purification step to remove co-leached metals, leading to a purified leachate suitable for zinc electrowinning. Zinc was leached from crushed MOVs using dilute sulfuric acid, which avoided co-leaching of antimony and bismuth but required further purification to remove co-leached cobalt and nickel. In further purification of the leachate, cementation was investigated. Initial findings suggest that the cobalt concentration can be reduced by over $50 \%(200 \mathrm{mg} / \mathrm{L})$ and nickel concentration reduced by over $90 \%(90 \mathrm{mg} / \mathrm{L})$, by optimizing the activator $(\mathrm{Sb} / \mathrm{Cu})$ concentration, temperature, $\mathrm{pH}$, and surface area of zinc dust. Further investigations into optimized batch addition of zinc and copperantimony activators verified that nearly $92 \%(>390 \mathrm{mg} / \mathrm{L})$ of the cobalt and all nickel $(100 \mathrm{mg} / \mathrm{L})$ can be removed from the acidic varistor leachate. These results suggest that cementation by addition of zinc dust can be used for purification of zinc solutions containing over $400 \mathrm{mg} / \mathrm{L}$ cobalt and $100 \mathrm{mg} / \mathrm{L}$ nickel and thus preparation of the solutions for zinc electrowinning.
\end{abstract}

The contributing editor for this article was Dimitrios Panias.

Toni Gutknecht

tonig@chalmers.se

1 Industrial Materials Recycling, Department of Chemistry and Chemical Engineering, Chalmers University of Technology, Kemivägen 4, 41296 Gothenburg, Sweden
Keywords Cementation - Activated cementation · Kinetics $\cdot$ Hydrometallurgy $\cdot$ Zinc $\cdot$ Purification $\cdot$ Metal oxide varistor

\section{Introduction}

In a sustainable system for use of materials, not only the production of goods needs to be sustainable, but also the management of residues and wastes. Brundtland [1] defines sustainability as, "the kind of development that meets the needs of the present without compromising the ability of future generations to meet their own needs." In Sweden, there is an initiative to recycle metal oxide varistors (MOVs) as opposed to landfilling them due to environmental concerns, rising costs of landfilling, awareness of the value of the material in the MOV, and the quantity of material available for recycling. As society realizes the importance of materials recycling and we move toward a circular use of materials versus linear research such as that presented here becomes very important in the sustainable production of goods. Currently, zinc is not a critical nor strategic metal [2] but its broad use throughout the world highlights its importance in society and thus the importance of identifying materials from which zinc can be recycled as well as a path for recycling, at the very least when economically feasible.

In 2013, one company in Sweden produced 132 tons of MOV [3] and in the last 5 years, 523 tons of MOV have been produced. Figure 1 shows the amount of MOV (in tons) produced from 2009 to 2013 as well as the composition of the MOV in terms of metal oxides. Considering this is only one company in a relatively small country the amount of MOV produced and eventually available for recycling is encouraging as a source of secondary zinc. The 


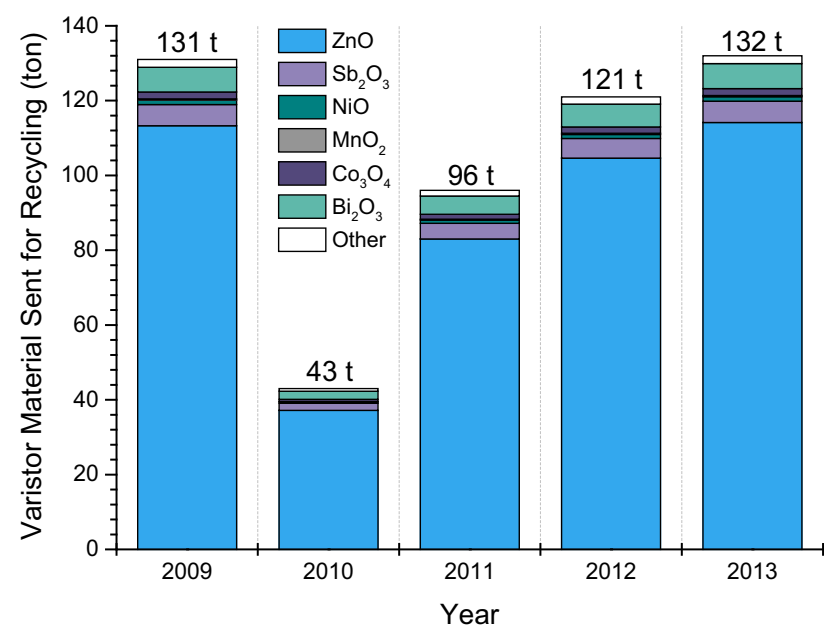

Fig. 1 Amount of MOV produced in Sweden during a 5-year period

used MOVs are primarily not mixed with other types of waste materials (at least in Sweden) but kept in a separate flow. This makes them an ideal case for a dedicated recycling method.

MOVs are housed in surge arrestors, which are important parts of power and rail systems, because they protect power systems from over voltages due to transients in the power grid [4]. The end of life surge arrestors can be disassembled, separating the MOVs from the surge arrestor housing. The MOV is composed mainly of zinc oxide ( $>90$ wt\%) [5-7] and also contains antimony (3-5 wt\%), bismuth (3-5 wt $\%$ ), cobalt ( $\sim 1 \mathrm{wt} \%)$, nickel ( $\sim 1 \mathrm{wt} \%)$, and manganese $(\sim 1 \mathrm{wt} \%)[5,6]$. Currently, there are no processes to recycle zinc from MOVs.

Today over $80 \%$ of the world's zinc is produced by roast-leach electrowinning [8]. Because electrowinning is highly sensitive to impurities in the electrolyte, the solution must first be purified [8-10]. Impurities in the zinc electrolyte lower the hydrogen over potential on zinc metal making the electrowinning process uneconomical due to lowered the current efficiency [11, 12]. Displacement of impurities in solution can be done through a reductionoxidation reaction known as cementation. In this case, zinc dust is added to the solution as a reducing agent. The overall reaction for cobalt cementation is given by Eq. 1 .

$\mathrm{Co}^{2+}+\mathrm{Zn} \rightarrow \mathrm{Co}+\mathrm{Zn}^{2+}$

Then, thermodynamically, cementation of cobalt as shown in Eq. 1 is favorable having an equilibrium constant, $K_{\mathrm{eq}}=2 \times 10^{16}$. However, in practice cementation of cobalt is very slow due to kinetic barriers. Activators such as copper and antimony are used to increase the rate of cobalt cementation and are thought to form an alloy with cobalt [13]. Fontana and Winand [13, 14] were able to identify $\mathrm{CoSb}$ and $\mathrm{CoSb}_{2}$ in the cementation product using
XRD. No diffraction peaks indicating the presence of metallic $\mathrm{Sb}$ or Co were observed.

Makimoto [12] developed an antimony and lead containing zinc dust for purification and proposed that on the antimony of the $\left.\mathrm{Zn}-\mathrm{Sb}_{(9.1-1.0} \%\right)-\mathrm{Pb}_{(0.5-5 \%)}$ alloy, cobalt is being reduced according to Eq. 2 and on the zinc of the $\left.\mathrm{Zn}-\mathrm{Sb}_{(9.1-1.0} \%\right)-\mathrm{Pb}_{(0.5-5} \%$ alloy zinc is being oxidized as shown by Eq. 3.

$\mathrm{Co}^{2+}+2 \mathrm{e}^{-} \rightleftharpoons \mathrm{Co}$

$\mathrm{Zn} \rightleftharpoons \mathrm{Zn}^{2+}+2 \mathrm{e}^{-}$

Blanders and Winland [15] proposed that cobalt forms an alloy with copper and antimony according to Eq. 4. For cementation, Eq. 4 is coupled with Eq. 5.

$$
\begin{aligned}
& \mathrm{Co}^{2+}+2 \mathrm{HSbO}_{2}+\mathrm{Cu}^{2+}+6 \mathrm{H}^{+}+10 \mathrm{e}^{-} \\
& \quad \rightarrow \mathrm{Cu}-\mathrm{Co}-\mathrm{Sb} \text { (alloy) }+4 \mathrm{H}_{2} \mathrm{O} \\
& \mathrm{Zn} \rightarrow \mathrm{Zn}^{2+}+2 \mathrm{e}^{-}
\end{aligned}
$$

Kroleva [16] suggested the formation of a $\mathrm{Cu}_{2} \mathrm{Sb}$ alloy which enhances cobalt formation shown in Eqs. 6 and 7.

$\mathrm{Zn}+\mathrm{Cu}_{2} \mathrm{Sb} \rightarrow \mathrm{Zn}^{2+}+\left(\mathrm{Cu}_{2} \mathrm{Sb}\right)^{2-}$

$\mathrm{Co}^{2+}+\left(\mathrm{Cu}_{2} \mathrm{Sb}\right)^{2-} \rightarrow \mathrm{Co}+\mathrm{Cu}_{2} \mathrm{Sb}$

Using potential-pH diagrams Tozawa et al. [12] suggested that cementation of cobalt with antimony and copper between $\mathrm{pH} 3-5$ proceeds according to Eq. 8 .

$$
\begin{gathered}
2 \mathrm{Co}^{2+}+2 \mathrm{HSbO}_{2}+6 \mathrm{H}^{+}+5 \mathrm{Zn} \\
\rightarrow 2 \mathrm{CoSb}+4 \mathrm{H}_{2} \mathrm{O}+5 \mathrm{Zn}^{2+}
\end{gathered}
$$

However, their investigation of the cementation product using scanning electron microscopy with energy dispersive X-ray spectroscopy (SEM-EDX) showed that copper and antimony co-existed but not with cobalt. The cobalt was found around the copper-antimony deposit.

Parameters that are known to affect cementation reactions are $\mathrm{pH}$, temperature, activator concentration, and zinc dust quantity [12, 13, 17-21]. Van der Pas et al. [17] concluded that the optimal conditions for cementation in a solution containing $30 \mathrm{mg} / \mathrm{L}$ cobalt were $30 \mathrm{mg} / \mathrm{L}$ copper and $1.5 \mathrm{mg} / \mathrm{L}$ antimony (both as activators) as well as addition of $4 \mathrm{~g} / \mathrm{L}$ zinc at a solution temperature of $70{ }^{\circ} \mathrm{C}$. Børve [20] suggested that optimal conditions for cobalt $(15 \mathrm{mg} / \mathrm{L})$ cementation arise when the solution contains $50-100 \mathrm{mg} / \mathrm{L}$ copper and $3-4 \mathrm{mg} / \mathrm{L}$ antimony (both as activators) with a solution temperature less than $80^{\circ} \mathrm{C}$. Work by Boyanov et al. [21] determined that maximum cobalt removal occurs at a temperature of $80-85^{\circ} \mathrm{C}$, copper concentration of $200-300 \mathrm{mg} / \mathrm{L}$, and 18 times the stoichiometric amount of zinc dust. According to their work [21], maximum removal of cobalt and nickel occurs when the $\mathrm{Sb}: \mathrm{Co}$ ratio is between 0.5:1 and 2:1. 
The concentration of cobalt in solution in many cementation investigations presented in the literature is approximately $20 \mathrm{mg} / \mathrm{L}[17,18,20]$. In the present work, the investigation was extended to solutions with cobalt concentrations of approximately $400 \mathrm{mg} / \mathrm{L}$. In addition, nearly $100 \mathrm{mg} / \mathrm{L}$ nickel is also present in the solution and needs to be removed via cementation. The cementation solution being investigated is produced from dilute, sulfuric acid leaching of pulverized MOV which contains higher concentrations of cobalt and nickel than zinc electrolytes commonly investigated. The aim was to investigate the feasibility of using cementation as a means for MOV leachate purification to make it suitable for zinc electrowinning. Since the MOV leaching solution contains $400 \mathrm{mg} / \mathrm{L}$ cobalt and $100 \mathrm{mg} / \mathrm{L}$ nickel, the optimal conditions from other studies [17, 18, 20, 21] were scaled up for this investigation. Present investigations included studies of the influence of temperature, $\mathrm{pH}$, activator concentration, and zinc dust surface area on the rate and extent of cobalt and nickel cementation.

\section{Experimental}

\section{Characterization}

The surface microstructure and morphology of the MOV were investigated. A FEI Quanta 200 environmental SEM equipped with an Oxford Inca energy-dispersive X-ray detector (EDX) system was used and imaging was done with accelerating voltages between 10 and $20 \mathrm{kV}$. A Bruker 2D Phaser X-ray diffractometer equipped with a copper radiation source and a scintillation detector was used to identify crystalline compounds present in the powder samples. Compound identification was made by comparisons with standards in the Joint Committee of Powder Diffraction Standards database [22]. The composition of the MOV was determined by complete dissolution in concentrated $\mathrm{HCl}$ (followed by analysis using InductiveCoupled Plasma with Optical Emission Spectrometric detection (ICP-OES)) (iCAP 6500, Thermo Fischer).

\section{MOV Leaching}

Bulk leaching experiments were started by bringing water (MilliQ, Millipore, $>18 \mathrm{M} \Omega / \mathrm{cm}$ ) in a straight wall beaker to $\mathrm{pH} 3$ by addition of $5 \mathrm{M} \mathrm{H}_{2} \mathrm{SO}_{4}$. The $5 \mathrm{M}$ sulfuric acid was made by dilution of concentrated $\mathrm{H}_{2} \mathrm{SO}_{4}$ (95.0-98.0\%) with milli-Q water. The beaker was equipped with a $\mathrm{pH}$ electrode, magnetic stirrer, and dosing device connected to a Metrohm 905 Titrando titrator connected to a computer for monitoring and controlling of the acid addition. The $\mathrm{pH}$ was monitored using a silver/silver chloride $(\mathrm{Ag} / \mathrm{AgCl})$ glass electrode. The temperature of the system was maintained at $20^{\circ} \mathrm{C} \pm 1$. Pulverized $(<63 \mu \mathrm{m})$ MOV was added to the $\mathrm{pH} 3$ solution causing the $\mathrm{pH}$ to rise. $5 \mathrm{M}$ sulfuric acid was titrated into the MOV-water mixture to maintain a leachate having a $\mathrm{pH}$ of 3 . The system was stirred so the stagnant layer around the solid particles could be perturbed ensuring mass transport from the liquid in the pores to the outer leachate where the $\mathrm{pH}$ and metal concentrations were measured.

The concentration of the leached metals in the solution was determined by taking an aliquot of the leaching solution, filtering it through a $0.45 \mu \mathrm{m}$ membrane and then analyzing using ICP-OES. The values obtained from ICPOES measurements were adjusted to account for dilution, acid addition, and volume lost due to sampling. Leaching experiments were done in triplicate to ensure experimental reproducibility. The leachate was separated from the insoluble residue by filtration using a Büchner funnel and filter with $0.45 \mu \mathrm{m}$ pore openings.

\section{Cementation Experiments}

To investigate cobalt and nickel removal from the MOV leachate, lab scale experiments were set up in the apparatus as shown schematically in Fig. 2. The apparatus was equipped with an $\mathrm{Ag} / \mathrm{AgCl} \mathrm{pH}$ electrode, stir bar, and dosing device connected to a Metrohm 905 Titrando titrator connected to a computer for monitoring and controlling the acid addition and $\mathrm{pH}$. To maintain the set $\mathrm{pH}$, $0.1 \mathrm{M} \mathrm{H}_{2} \mathrm{SO}_{4}$ solution was dispensed into the reaction vessel containing the cementation solution. Typical cementation experiments were carried out at $20 \pm 1{ }^{\circ} \mathrm{C}$. Nitrogen was bubbled through the cementation solution to remove dissolved oxygen.

For each cementation experiment, $25 \mathrm{~mL}$ of $\mathrm{MOV}$ leachate was used. Copper $\left(\mathrm{CuSO}_{4} \cdot 5 \mathrm{H}_{2} \mathrm{O},>99.0\right)$ and antimony $\left(\mathrm{K}_{2} \mathrm{C}_{8} \mathrm{H}_{4} \mathrm{O}_{12} \mathrm{Sb}_{2} \cdot 3 \mathrm{H}_{2} \mathrm{O}, 99.95 \%\right)$ were added to the leachate as activators. A summary of cementation parameters studied is given Table 1. Zinc dust (325 mesh, $99.9 \%$ ) was added to the reaction vessel initiating the cementation experiment $(t=0)$. From the time of zinc dust addition $(t=0)$, samples were taken at $t=5,10,20,30$, 60,90 , and $120 \mathrm{~min}$. The amount of zinc dust added was typically between 1 and 2 times the stoichiometric amount needed for cementation of cobalt, nickel, copper, and antimony. Each sample was filtered through a $25-\mathrm{mm}$ syringe filter with $0.45 \mu \mathrm{m}$ polypropylene membrane and diluted for ICP-OES analysis of the metal ion concentration.

To determine the surface area of the zinc dust, a surface area and porosity analyzer (Micrometrics, ASAP 2020) were used. Zinc dust was placed inside a vessel and the surface area was measured as a function of nitrogen gas 


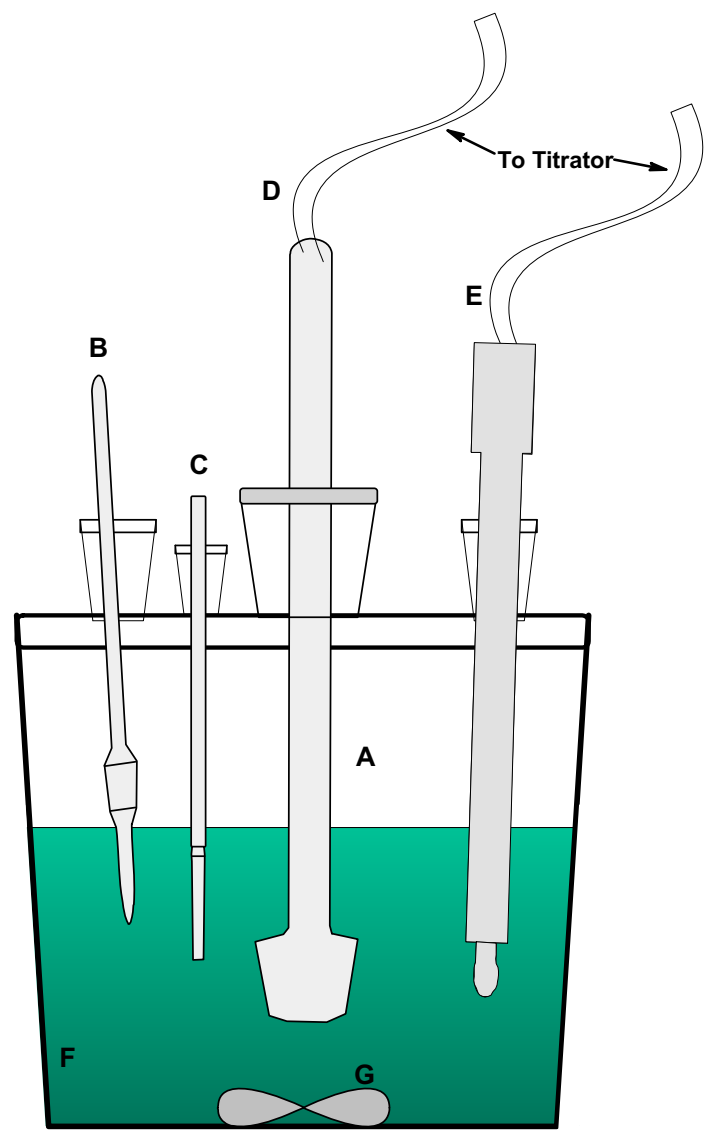

Fig. 2 Apparatus used during cementation experiments. a Cementation cell, $\mathbf{b}$ device for solution sampling, $\mathbf{c}$ nitrogen gas inlet, $\mathbf{d}$ dosing device, e pH electrode, $\mathbf{f}$ MOV leachate, and $\mathbf{g}$ stir bar

(adsorbate) adsorbed on the surface of the zinc according to the Brunauer-Emmett-Teller (BET) theory. BET measurements show that the surface area per gram of zinc dust is $0.2268 \pm 0.0031 \mathrm{~m}^{2} / \mathrm{g}$.

\section{Results and Discussion}

\section{Characterization of MOV}

Typically, MOVs contain approximately $90 \mathrm{wt} \% \mathrm{ZnO}$, around $3 \mathrm{wt} \%$ of both $\mathrm{Bi}_{2} \mathrm{O}_{3}$ and $\mathrm{Sb}_{2} \mathrm{O}_{3}$, with other metal oxides accounting for the remaining $4 \mathrm{wt} \%$ [23, 24]. The dissolved MOV investigated in this work contained, in detectable amounts, the metals listed in Table 2 shown as gram of metal per gram of MOV.

The microstructure of the MOV contains the three major phases: Phase I, a zinc-rich phase containing $\mathrm{ZnO}$ grains; Phase II, an antimony-rich phase made up of spinel $\left(\mathrm{Zn}_{7}\right.$ $\left.\mathrm{Sb}_{2} \mathrm{O}_{12}, \mathrm{Zn}_{2.33} \mathrm{Sb}_{0.67} \mathrm{O}_{4}\right)$ and pyrochlore $\left(\mathrm{Zn}_{2} \mathrm{Bi}_{3} \mathrm{Sb}_{3} \mathrm{O}_{14}\right)$; and Phase III, a bismuth-rich phase containing $\mathrm{Bi}_{2} \mathrm{O}_{3}$. A SEM micrograph of a pulverized MOV particle is shown in Fig. 3 with an overlay of EDX maps for zinc (red), antimony (green), and bismuth (blue).

Result from qualitative mineralogical analysis of the MOV using XRD confirms the presence of $\mathrm{ZnO}, \mathrm{Bi}_{2} \mathrm{O}_{3}$, $\mathrm{Zn}_{2.33} \mathrm{Sb}_{0.67} \mathrm{O}_{4}, \mathrm{Zn}_{2} \mathrm{Bi}_{3} \mathrm{Sb}_{3} \mathrm{O}_{14}$, and $\mathrm{Zn}_{7} \mathrm{Sb}_{2} \mathrm{O}_{12}$. Compounds containing cobalt, manganese , and nickel were not confirmed due to their low concentrations.

Table 2 Chemical composition of MOV

\begin{tabular}{ll}
\hline Metal & $\mathrm{g} / \mathrm{g}$ \\
\hline $\mathrm{Bi}$ & $0.0459 \pm 0.0001$ \\
$\mathrm{Co}$ & $0.0069 \pm 0.0001$ \\
$\mathrm{Mn}$ & $0.0036 \pm 0.0001$ \\
$\mathrm{Ni}$ & $0.0061 \pm 0.0001$ \\
$\mathrm{Sb}$ & $0.0348 \pm 0.0011$ \\
$\mathrm{Zn}$ & $0.7615 \pm 0.0036$ \\
\hline
\end{tabular}

Table 1 List of cementation experiments and the parameters which were studied

\begin{tabular}{lll}
\hline Experiment & Constant parameters & Varied parameter \\
\hline Influence of $\mathrm{Cu}$ concentration & $\mathrm{No} \mathrm{Sb}$ & $\mathrm{Cu}$ conc. $(\mathrm{g} / \mathrm{L}): 0.2,0.4,0.8,1.2$ \\
& $2 \mathrm{~g} / \mathrm{L} \mathrm{Zn} \mathrm{dust}$ & \\
Influence of $\mathrm{Cu}$ concentration & $0.4 \mathrm{~g} / \mathrm{L} \mathrm{Sb}$ & $\mathrm{Cu}$ Conc. $(\mathrm{g} / \mathrm{L}): 0.2,0.4,0.8,1.6$ \\
& $2 \mathrm{~g} / \mathrm{L} \mathrm{Zn} \mathrm{dust}$ & \\
Influence of Sb concentration & $0.4 \mathrm{~g} / \mathrm{L} \mathrm{Cu}$ & Sb Conc. $(\mathrm{g} / \mathrm{L}): 0.1,0.2,0.4,0.8,1.6$ \\
& $2 \mathrm{~g} / \mathrm{L} \mathrm{Zn} \mathrm{dust}$ & \\
Influence of temperature & $0.4 \mathrm{~g} / \mathrm{L} \mathrm{Sb}$ & Temperature $\left({ }^{\circ} \mathrm{C}\right): 30,40,50,55,60$ \\
& $0.4 \mathrm{~g} / \mathrm{L} \mathrm{Cu}$ & \\
Influence of $\mathrm{Zn}$ dust addition & $2 \mathrm{~g} / \mathrm{L} \mathrm{Zn} \mathrm{dust}$ & \\
Influence of $\mathrm{pH}$ & $0.4 \mathrm{~g} / \mathrm{L} \mathrm{Sb}$ & $\mathrm{Zn}$ dust conc. $(\mathrm{g} / \mathrm{L}): 0.25,0.5,1,2,3,4$ \\
& $0.4 \mathrm{~g} / \mathrm{L} \mathrm{Cu}$ & \\
& $0.4 \mathrm{~g} / \mathrm{L} \mathrm{Sb}$ & $\mathrm{pH}: 3.0,3.5,4.0,4.5,5.0,5.5,6.0$
\end{tabular}




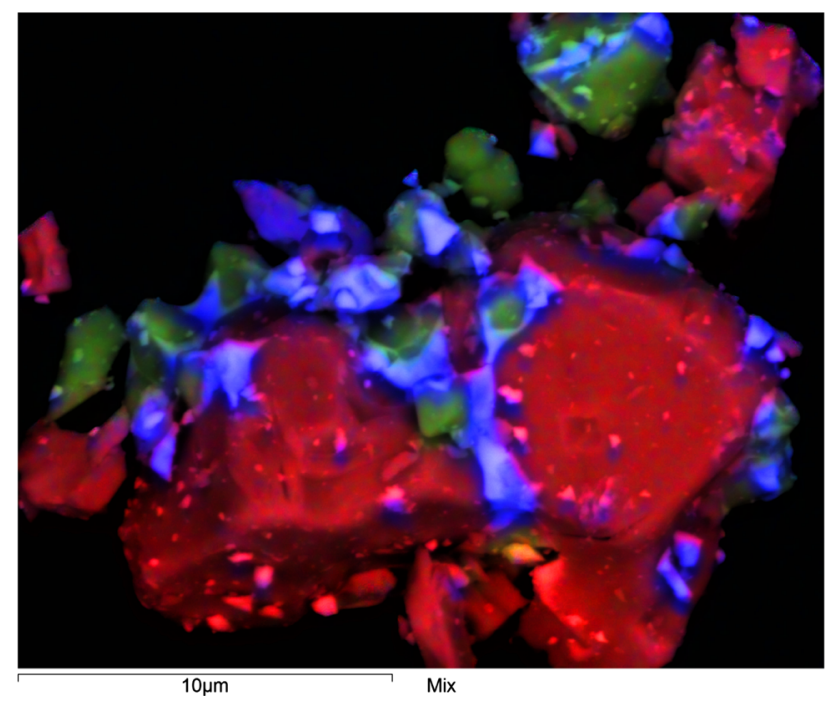

Fig. 3 Combined SEM micrograph and EDX map for Phase I-zinc oxide phase (red), Phase II-antimony-rich phase (green), and Phase III—bismuth oxide phase (blue) (Color figure online)

\section{Cementation Solution: Leaching of MOV}

Leaching of the MOVs was based on a method for dilute sulfuric acid that was optimized for zinc leaching in previous work by Gutknecht et al. [6]. For this work, the leaching results are shown in Fig. 4a which displays the volume of $5 \mathrm{M} \mathrm{H}_{2} \mathrm{SO}_{4}$ added during the leaching experiment and Fig. $4 \mathrm{~b}$ showing the $\mathrm{pH}$ change as a function of

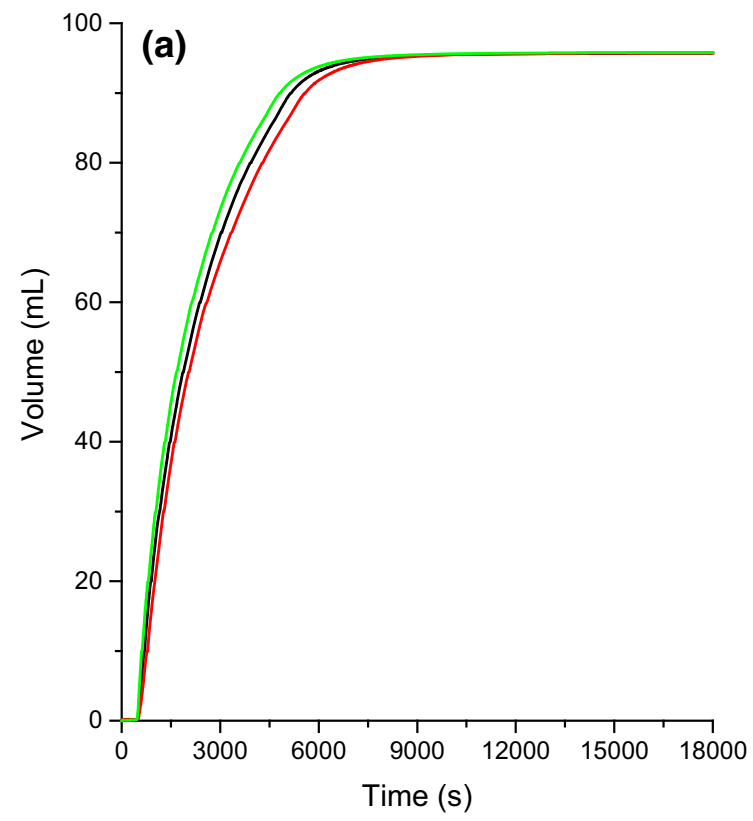

time for the three bulk MOV leaching experiments. After $4 \mathrm{~h}$, the $\mathrm{pH}$ remained constant at $\mathrm{pH} 3$ indicating the consumption of hydrogen ions had ceased.

The average volume of $5 \mathrm{M} \mathrm{H}_{2} \mathrm{SO}_{4}$ added during the leaching experiments was $95.75 \pm 0.04 \mathrm{~mL}$. Once the leaching was done, the leachate was separated from the residue and analyzed by ICP-OES yielding a leachate having concentrations as found in Table 3. For comparison, typical metal concentrations in a metal solution prepared for industrial zinc electrowinning by cementation are also shown in Table 2 as well as the concentration of metal prior to cementation. For the MOV leachate to be easily integrated into an industrial zinc electrowinning process, significant amounts of impurities need to be removed. It has been reported that $15 \mathrm{mg} / \mathrm{L}$ of cobalt, copper, and nickel can reduce the current efficiency by 10,15 , and $40 \%$, respectively, in this process [13].

\section{Cementation Experiments}

\section{Influence of Copper Ion Concentration}

Work by Van der Pas et al. showed that cementation of cobalt by zinc dust addition without antimony or copper being present in the solution resulted in less than $10 \%$ of the cobalt being removed [17]. Their results also show that addition of copper alone to the cementation solution did not result in improved cementation of cobalt. When both copper and antimony ions were present the removal of

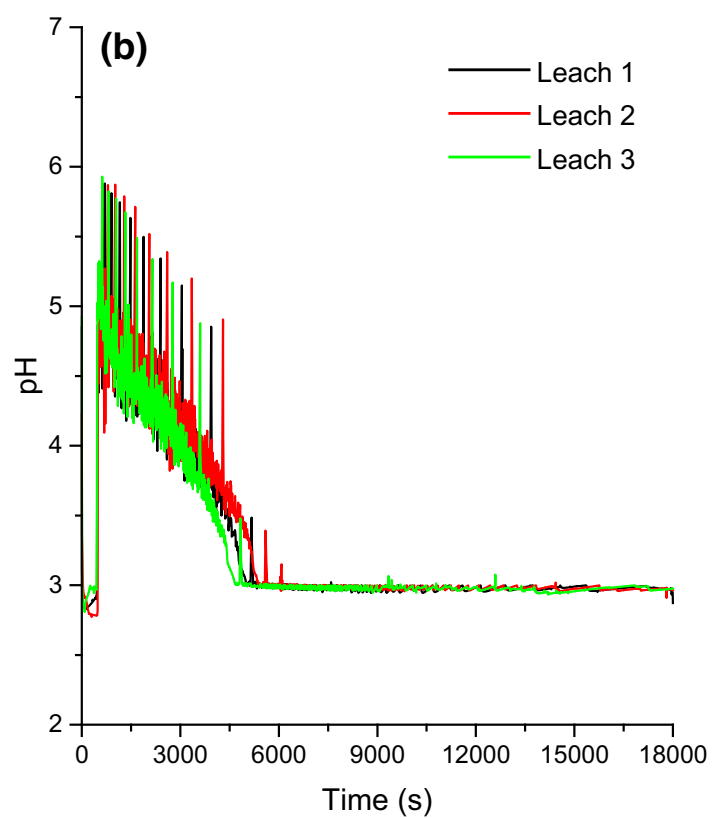

Fig. 4 a Amount of $5 \mathrm{M} \mathrm{H}_{2} \mathrm{SO}_{4}$ solution added during bulk MOV leaching experiment versus time. b The pH versus time during the bulk leaching experiments 
Table 3 Concentration of metals in leachate for the elements found in the MOV along with industrial zinc electrowinning solution concentrations before and after cementation

\begin{tabular}{llll}
\hline Element & MOV leachate $(\mathrm{mg} / \mathrm{L})$ & $\begin{array}{l}\text { Industrial electrolyte before } \\
\text { cementation [13] }(\mathrm{mg} / \mathrm{L})\end{array}$ & $\begin{array}{l}\text { Industrial electrolyte after } \\
\text { cementation [13] }(\mathrm{mg} / \mathrm{L})\end{array}$ \\
\hline $\mathrm{Bi}$ & 0 & 0 & 0 \\
$\mathrm{Co}$ & $437 \pm 8$ & 15 & $1-0.05$ \\
$\mathrm{Cu}$ & 0 & 1000 & $0.1-0.15$ \\
$\mathrm{Mn}$ & $68 \pm 1$ & 0 & 0 \\
$\mathrm{Ni}$ & $106 \pm 2$ & 0 & 0 \\
$\mathrm{Sb}$ & 0 & 0 & $0.01-0.02$ \\
$\mathrm{Zn}$ & $81100 \pm 1590$ & $\sim 150,000$ & $\sim 150,000$ \\
\hline
\end{tabular}

cobalt increased by a factor of 18 . However, it has been reported that the effect of copper improves the cobalt cementation rate if only slightly [13].

The results for cobalt and nickel from the present work are shown in Fig. 5. In addition to the metal ions in the leaching solution, copper was added in four concentrations: $0.2,0.4,0.8$, and $1.2 \mathrm{~g} / \mathrm{L}$. The initial $\mathrm{pH}$ of the cementation solution was $\mathrm{pH} 3$. It increased due to the zinc dust addition and was held constant at $\mathrm{pH} 4$ for cementation. The diagrams in Fig. 3 show the metal concentrations in solution as a function of time.

In these experiments, i.e., in the presence of copper but with no antimony, less than $10 \%$ of cobalt was removed from solution no matter the amount of copper present. For nickel nearly $30 \%$ was removed in the presence of copper but the kinetics of nickel removal is slow. The cementation rate of nickel is inversely related to the copper concentration in solution.

The next set of experiments were carried out with addition of antimony in one concentration $(0.4 \mathrm{~g} / \mathrm{L})$ and the same concentrations of copper in the solution as in the previous experiments. Boyanov et al. [18] determined that when the Sb:Co molar ratio is between $0.5: 1$ and 2:1, the solution is purified from cobalt and nickel to the greatest degree. In this work, a 1:1 (Sb:Co) molar ratio was used and the results obtained are shown in Fig. 6.

Addition of antimony $(0.4 \mathrm{~g} / \mathrm{L})$ and copper $(0.2 \mathrm{~g} / \mathrm{L})$ resulted in nearly $140 \mathrm{mg} / \mathrm{L}$ of cobalt and $50 \mathrm{mg} / \mathrm{L}$ of nickel to be cemented. In both cases, with and without antimony present (Figs. 3, 4), increasing the copper concentration resulted in lower amount of metals removed from solution. This is due to the reaction of copper ions with the zinc metal surfaces. The rate of reduction occurred faster for copper and antimony ions than for cobalt and nickel ions as seen from ICP-OES data. At higher copper concentrations, the zinc surface was covered in copper eliminating the reaction sites available for cementation to take place. The results in this work are in agreement with Boyanov et al. [18] in that the addition of copper did not significantly improve cobalt cementation.

\section{Influence of Antimony Concentration}

It has been shown that activators such as antimony and copper must be present in the solution for cementation reactions to occur to a large degree. In industry, antimony
Fig. 5 Influence of copper concentration on cementation of cobalt and nickel with copper concentrations of $0.2,0.4,0.8$, and $1.2 \mathrm{~g} / \mathrm{L}, T=20^{\circ} \mathrm{C}, \mathrm{pH} 4$, and $2 \mathrm{~g} / \mathrm{L}$ zinc dust
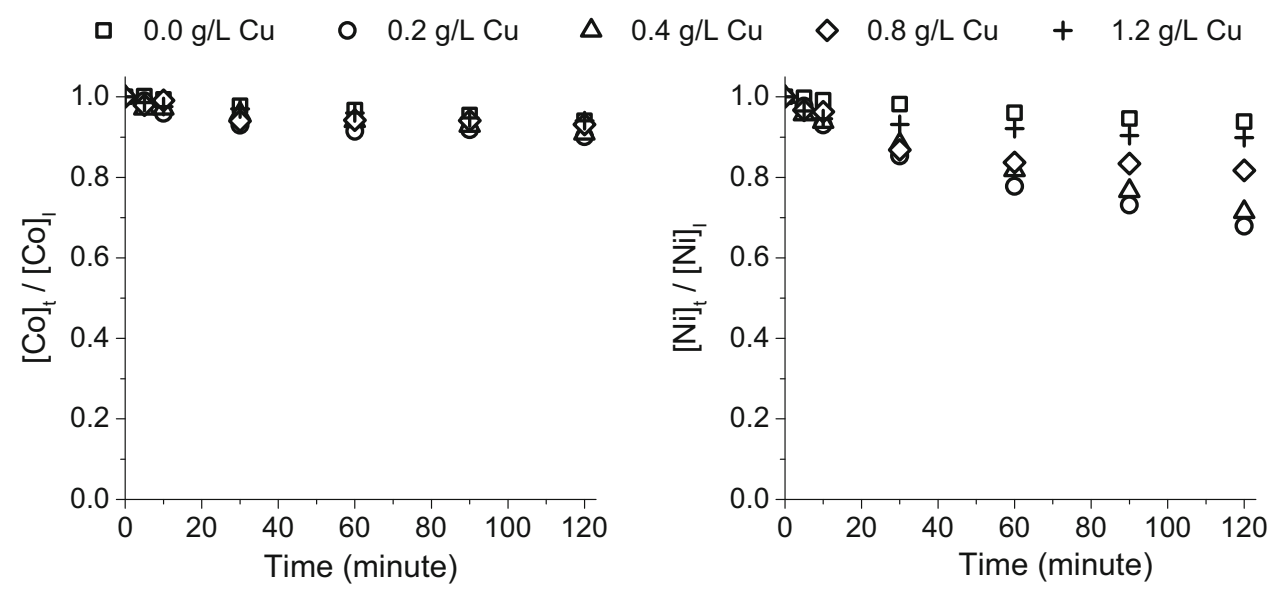
Fig. 6 Influence of copper concentration in the presence of $0.4 \mathrm{~g} / \mathrm{L}$ antimony on cementation of cobalt and nickel with copper concentrations of $0.2,0.4,0.8$, and $1.4 \mathrm{~g} / \mathrm{L}$, $T=20^{\circ} \mathrm{C}, \mathrm{pH} 4$, and $2 \mathrm{~g} / \mathrm{L}$ zinc dust

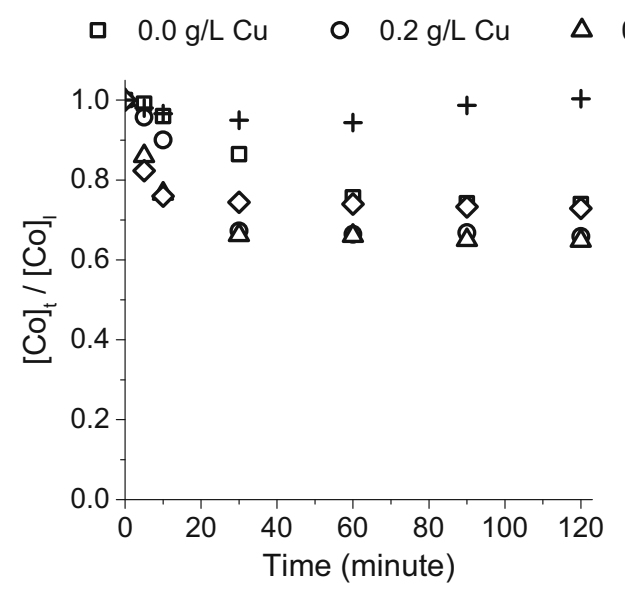

$\Delta 0.4 \mathrm{~g} / \mathrm{LCu} \diamond 0.8 \mathrm{~g} / \mathrm{LCu}+1.6 \mathrm{~g} / \mathrm{LCu}$

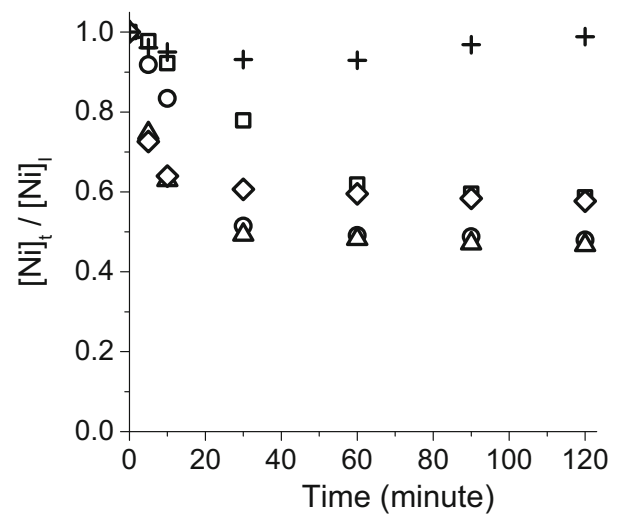

is known as an activator which helps to speed up the slow kinetics of cobalt cementation on zinc making this type of purification process feasible [19]. It has been reported that copper together with antimony forms a substrate favorable for cobalt cementation by copper forming a larger cathodic area on the zinc dust. In addition, antimony has been shown to increase the amount of cobalt in the deposit by forming a Sb-Co alloy [13].

To investigate the influence of antimony, five concentrations $0.1,0.2,0.4,0.8$, and $1.6 \mathrm{~g} / \mathrm{L}$ of antimony along with $0.4 \mathrm{~g} / \mathrm{L}$ copper were used. Cementation results are shown in Fig. 7 for cobalt and nickel. When $0.8 \mathrm{~g} / \mathrm{L}$ of antimony was present, $38 \%$ of cobalt and $67 \%$ of nickel were removed from solution.

Increasing the concentration of antimony increased the amount of cobalt cemented from less than $10 \%$ (no antimony) to nearly $40 \%$ using $0.8 \mathrm{~g} / \mathrm{L}$ of antimony as shown in Fig. 7a. However, addition of $1.6 \mathrm{~g} / \mathrm{L}$ antimony to the cementation solution had adverse effects on the cementation of both cobalt and nickel. This trend is not reported in the literature where antimony was added in lower concentrations. However, in work done by Jun et al. [25], addition of more than $5 \mathrm{mg} / \mathrm{L}$ antimony to the solution did not increase the rate of cobalt cementation in a $24 \mathrm{~g} / \mathrm{L}$ solution of cobalt and addition of $6 \mathrm{mg} / \mathrm{L}$ antimony caused re-dissolution of cobalt at $85{ }^{\circ} \mathrm{C}$. The results by Jun et al. as well as the results obtained in Fig. 7 suggest that there is a maximum concentration of antimony that can be added before adverse conditions for cobalt cementation exist.

From ICP-OES data, it was shown that after $10 \mathrm{~min}$ all copper and antimony have been removed from solution. Similarly, after $30 \mathrm{~min}$, the amount of cobalt cemented from solution did not increase. Similar reaction kinetics of copper and antimony were also seen by Van der Pas et al. [17]. This indicates the formation of an alloy of copperantimony-cobalt promoting the cementation of cobalt as suggested by Kroleva et al. [16] in Eqs. 6-7.

\section{Influence of Temperature}

Temperature is by far the most influential parameter in cementation as reported in the work of others [26, 27]. Higher temperature results in a faster rate of cobalt cemented from the solution due to increased reaction
Fig. 7 Influence of antimony concentration on cementation of cobalt and nickel with copper concentration of $0.4 \mathrm{~g} / \mathrm{L}$ and antimony concentrations of 0.1 , $0.2,0.4,0.8$, and $1.6 \mathrm{~g} / \mathrm{L}$, $T=20^{\circ} \mathrm{C}, \mathrm{pH} 4$, and $2 \mathrm{~g} / \mathrm{L}$ zinc dust
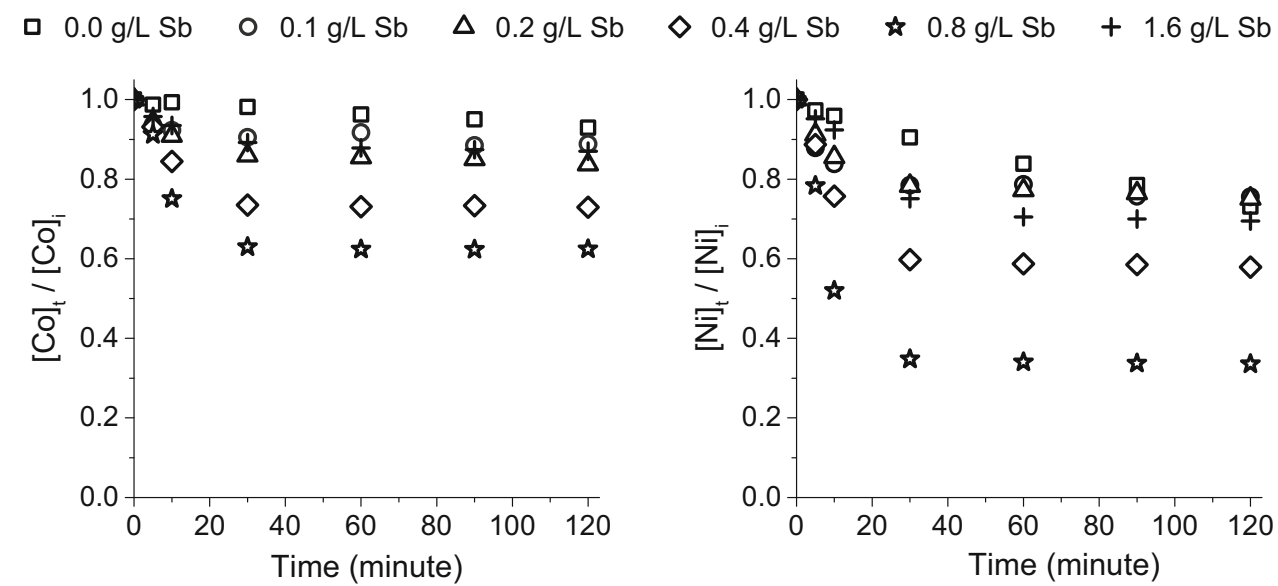
Fig. 8 Influence of temperature $\left(T=20,30,40,50,60^{\circ} \mathrm{C}\right)$ on cementation of cobalt and nickel with copper and antimony concentrations of $0.4 \mathrm{~g} / \mathrm{L}, \mathrm{pH} 4$, and $2 \mathrm{~g} / \mathrm{L}$ zinc dust

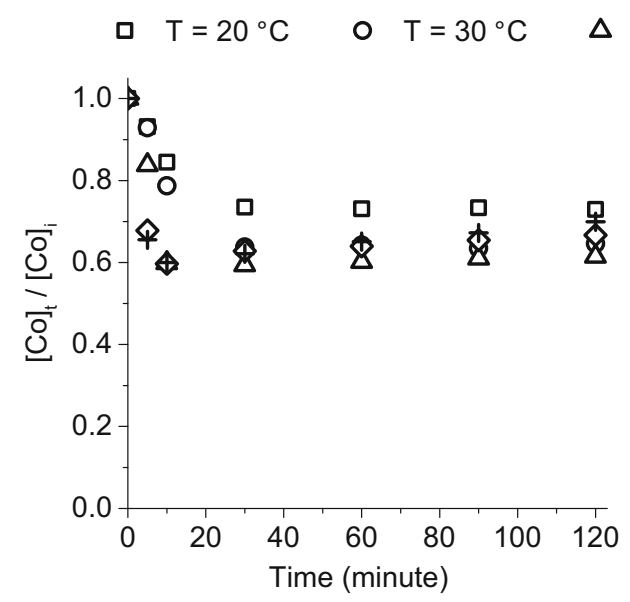

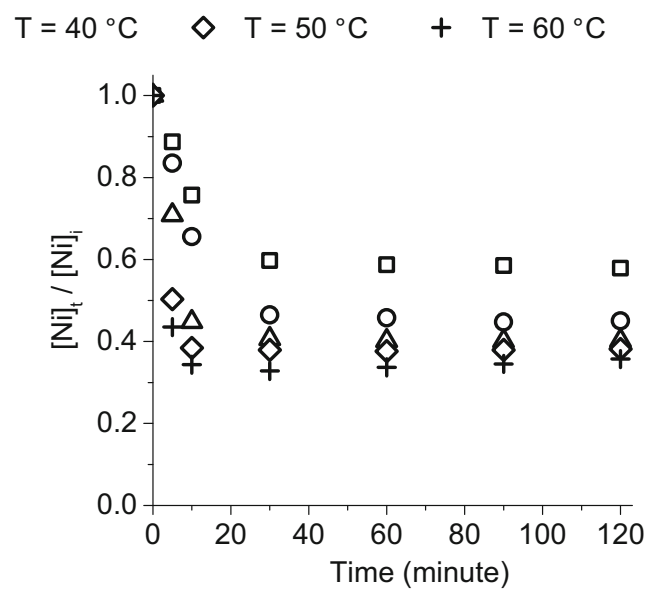

kinetics. Literature suggests that the optimal temperature for cobalt cementation is between 75 and $90{ }^{\circ} \mathrm{C}$ $[10,25,28]$. Industrially, temperatures higher than $70^{\circ} \mathrm{C}$ are used for cobalt cementation but it has been seen by Van der Pas et al. [17] that once above $85^{\circ} \mathrm{C}$ hydrogen evolution retards the cobalt cementation.

Experiments were carried out at temperatures of 20,30, 40, 50, and $60{ }^{\circ} \mathrm{C}$. The results are shown in Fig. 8 for cobalt and nickel. The cementation solutions contained copper and antimony with a concentration of $0.4 \mathrm{~g} / \mathrm{L}$ each.

Temperature did not have a significant effect on the amount of antimony and nickel cemented from solution but the kinetics increased with temperature as indicated in Fig. 8. However, literature suggests the optimal temperature for cobalt cementation is near $80^{\circ} \mathrm{C}$. Cementation of cobalt at higher temperatures resulted in the occurrence of a maximum in cobalt removal. A maximum of $41 \%$ cobalt and $59 \%$ of nickel was removed from solution after $30 \mathrm{~min}$ at $40{ }^{\circ} \mathrm{C}$. While after $120 \mathrm{~min}$ at $40{ }^{\circ} \mathrm{C}, 38 \%$ of cobalt and $60 \%$ of nickel were removed. There can be several reasons for the maxima: higher temperatures resulting in an increased rate of hydrogen production at the zinc surface, evaporation of leachate, and cobalt re-dissolution at elevated temperatures [21, 29].

\section{Influence of the Amount of Zinc Dust Present}

The influence on the amount of zinc dust added to the MOV leachate system was largely unknown due to the higher concentration of impurities in the MOV leachate as compared to industrial zinc electrolytes. Industrially, 4-6 g/L of zinc dust is used for cementation of approximately $20 \mathrm{mg} / \mathrm{L}$ cobalt [13]. Experiments were conducted with the amount of zinc dust added being between 0.25 and $4 \mathrm{~g} / \mathrm{L}$. However, it is not the amount of zinc dust added but rather the surface area that affects the cementation reactions. BET measurements showed that the surface area per
Table 4 Quantity of zinc dust added during cementation experiments with correlating surface area

\begin{tabular}{lc}
\hline $\begin{array}{l}\text { Concentration of } \mathrm{Zn} \\
\text { dust added }(\mathrm{g} / \mathrm{L})\end{array}$ & $\begin{array}{l}\text { Surface area of } \\
\text { Zn dust }\left(\mathrm{cm}^{2}\right)\end{array}$ \\
\hline 0.25 & $14.5 \pm 0.2$ \\
0.5 & $28.4 \pm 0.4$ \\
1 & $56.9 \pm 0.8$ \\
2 & $113 \pm 2$ \\
3 & $171 \pm 2$ \\
4 & $228 \pm 3$ \\
\hline
\end{tabular}

gram of zinc dust in these experiments was $0.2268 \pm 0.0031 \mathrm{~m}^{2} / \mathrm{g}$. The amount of zinc dust and the equivalent surface area of the zinc dust added to the cementation solution is given in Table 4.

Some literature data give the amount of zinc dust added not in surface area $\left(\mathrm{cm}^{2}\right)$ but in concentration $(\mathrm{g} / \mathrm{L})$. This does not allow accurate comparison of results between studies as the geometry and particle size distribution of the zinc dust varies by preparation method.

For this work, a zinc dust with spherical particles was used, as shown in Fig. 9 where the particle size of the zinc used is below $20 \mu \mathrm{m}$. It has been reported that, in general, smaller zinc dust particles result in faster kinetics and lower cobalt concentrations [20]. Cementation results for cobalt and nickel and the influence of zinc dust surface area are shown in Fig. 10.

The amount of zinc dust added to the cementation solution had a significant effect on the amount of cobalt and nickel removed. When using less than $1 \mathrm{~g} / \mathrm{L}$ of zinc dust $\left(56.9 \pm 0.78 \mathrm{~cm}^{2}\right)$ not enough surface area was available for cementation reactions to take place and as a result the zinc surface was immediately covered by copper and antimony. This was concluded from ICP-OES data which showed that antimony and copper remained in 


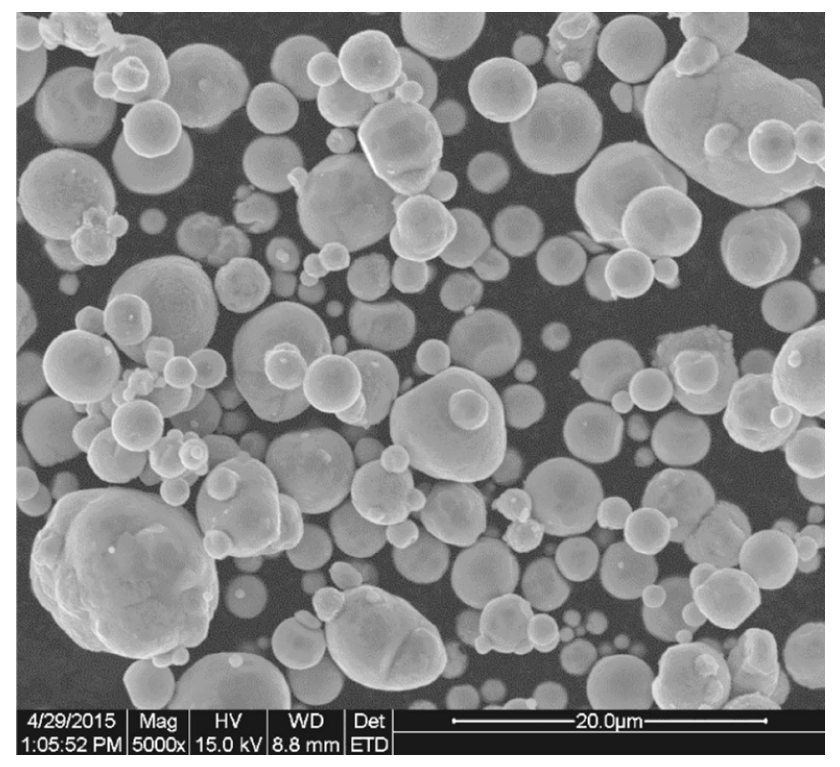

Fig. 9 SEM of zinc dust used in cementation reactions

solution when using low concentrations of zinc dust. When the largest amount of zinc dust was added $(4 \mathrm{~g} / \mathrm{L}$, $\left.228 \pm 3 \mathrm{~cm}^{2}\right) 48 \%$ of cobalt and $63 \%$ of nickel were cemented from solution. The cementation trend observed in Fig. 10 for cobalt and nickel may be caused from an increased number of active sites on the zinc dust surface.

\section{Influence of $\mathrm{pH}$}

The effect of variation in $\mathrm{pH}$ on the cementation reactions was investigated between $\mathrm{pH} 3.0$ and $\mathrm{pH} 6.0$ and the results for cobalt and nickel are shown in Fig. 11.

A cementation solution maintained at $\mathrm{pH}$ 5.0-5.5 gave the most effective removal of cobalt and nickel with $52 \%$ of cobalt and $74 \%$ of nickel removed. Using a pH higher than 6.0 had a negative impact on cementation due to formation of basic zinc salts. If the $\mathrm{pH}$ of the solution is too high (typically higher than $\mathrm{pH}$ 5.0), the formation of basic zinc sulfate or zinc hydroxide inhibits the reaction kinetics by forming a passivating layer on the zinc particles $[9,19,29]$.

\section{Optimized Cementation}

From the experiments described in previous sections where the influence of parameters such as copper concentration, antimony concentration, zinc dust addition, temperature, and $\mathrm{pH}$ were studied; it can be concluded that the optimal conditions for cementation of cobalt are $0.8 \mathrm{~g} \mathrm{~L}^{-1} \mathrm{Sb}$, $0.4 \mathrm{~g} \mathrm{~L}^{-1} \mathrm{Cu}, T=40^{\circ} \mathrm{C}, 0.2 \mathrm{~g} \mathrm{~L}^{-1} \mathrm{Zn}$ addition, and a solution $\mathrm{pH}$ of 5.0. These conditions obtained were applied to obtain optimal conditions for cementation purification of the MOV leachate at room temperature and $40{ }^{\circ} \mathrm{C}$, and the results are shown in Fig. 12.

Figure 12 shows that it is possible to purify MOV sulfuric acid based leach solutions with respect to nickel via cementation reactions. Over $90 \%$ of nickel was removed. Even though copper and antimony are added to the cementation solution as activators, they are easily removed causing no contamination to the leachate. The concentration of cobalt in solution was reduced by $57 \%$. The starting and final concentration of metals in the leachate at 20 and $40{ }^{\circ} \mathrm{C}$ are shown in Table 5.

It seems probable that the cementation of cobalt and nickel is dependent on the presence of copper and antimony in solution. However, in the cementation experiments, it was seen that all dissolved copper and antimony were consumed within $10 \mathrm{~min}$. Batch addition of these two metals along with more zinc dust after 60 min reaction time was further investigated with the results as shown in Fig. 13. The solution initially contained $0.8 \mathrm{~g} / \mathrm{L}$ of antimony and $0.4 \mathrm{~g} / \mathrm{L}$ of copper. $2 \mathrm{~g} / \mathrm{L}$ of zinc dust was added at $t=0$. The cementation reaction proceeded for $60 \mathrm{~min}$ and was stopped by filtering the solution and removing the
Fig. 10 Results for the influence of zinc dust addition $(0.25,0.5,1,2,3,4 \mathrm{~g} / \mathrm{L} \mathrm{Zn})$ on cementation of cobalt and nickel, with copper and antimony concentrations of $0.4 \mathrm{~g} / \mathrm{L}$ at $T=20^{\circ} \mathrm{C}, \mathrm{pH} 4$
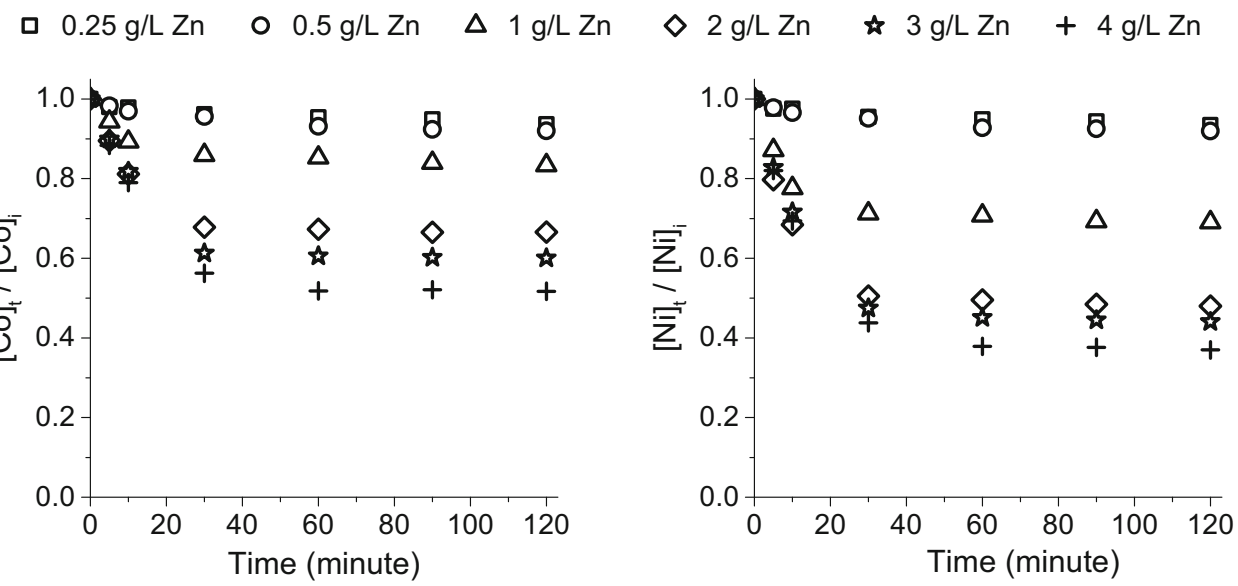
Fig. 11 Results for the influence of solution $\mathrm{pH}$ on cementation cobalt and nickel with copper and antimony concentrations of $0.4 \mathrm{~g} / \mathrm{L}$ at $T=20{ }^{\circ} \mathrm{C}, \mathrm{pH} 4$, and $2 \mathrm{~g} / \mathrm{L}$ zinc dust

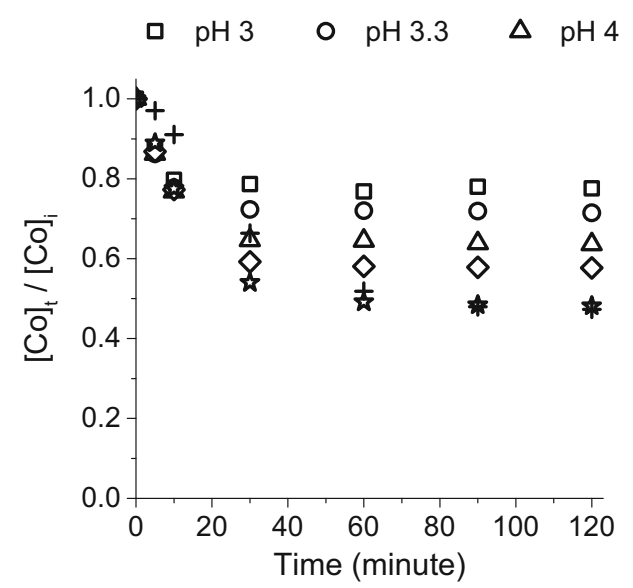

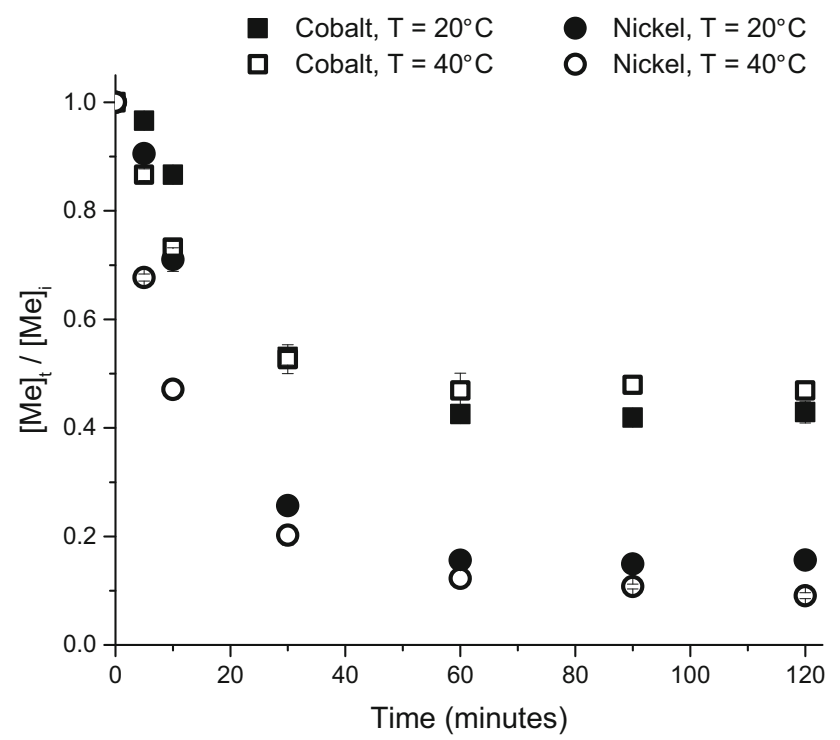

Fig. 12 Cementation with addition of $0.8 \mathrm{~g} / \mathrm{L} \mathrm{Sb}, 0.4 \mathrm{~g} / \mathrm{L} \mathrm{Cu}, 2 \mathrm{~g} / \mathrm{L}$ $\mathrm{Zn}$, at $\mathrm{pH} 5$

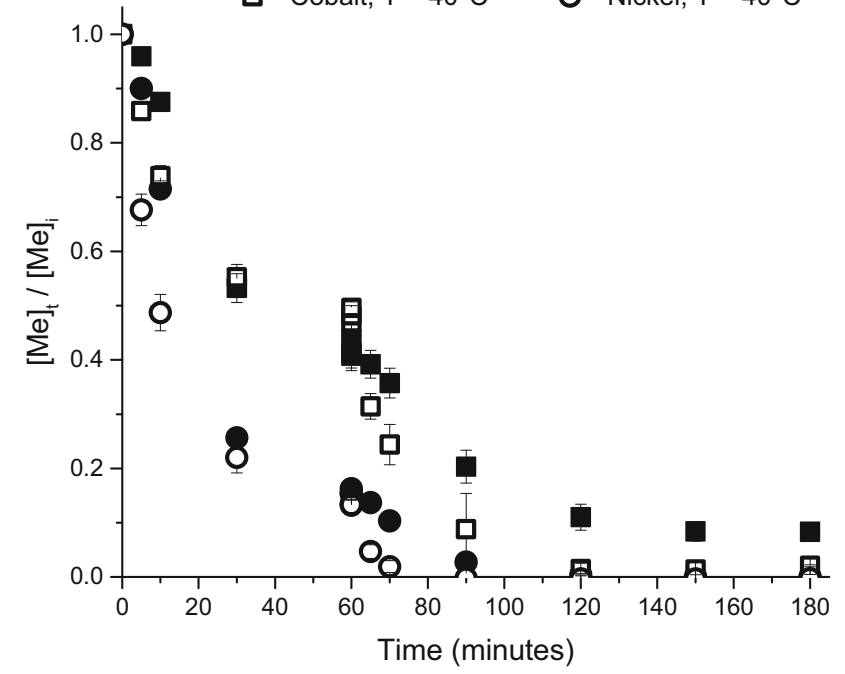

Fig. 13 Cementation with 2 batch additions of $0.8 \mathrm{~g} / \mathrm{L} \mathrm{Sb}, 0.4 \mathrm{~g} / \mathrm{L}$ $\mathrm{Cu}, 2 \mathrm{~g} / \mathrm{L} \mathrm{Zn}$, at $\mathrm{pH} 5$

Table 5 Concentration of metals in MOV leachate before and after optimized cementation

\begin{tabular}{llrr}
\hline Metal & Pre-cementation & \multicolumn{2}{l}{ Post-cementation } \\
\cline { 3 - 4 } & Metal concentration $(\mathrm{mg} / \mathrm{L})$ & $\begin{array}{l}\text { Metal concentration } \\
\text { at } T=2{ }^{\circ} \mathrm{C}(\mathrm{mg} / \mathrm{L})\end{array}$ & $\begin{array}{l}\text { Metal concentration } \\
\text { at } T=40^{\circ} \mathrm{C}(\mathrm{mg} / \mathrm{L})\end{array}$ \\
\hline $\mathrm{Co}$ & $423 \pm 14$ & $185.5 \pm 6.8$ & $194.1 \pm 9.0$ \\
$\mathrm{Cu}$ & $378 \pm 24$ & $0.1 \pm 0.7$ & $0.0 \pm 0.7$ \\
$\mathrm{Mn}$ & $60.7 \pm 2.1$ & $57.9 \pm 0.6$ & $62.1 \pm 0.5$ \\
$\mathrm{Ni}$ & $96.8 \pm 5.7$ & $15.5 \pm 1.1$ & $8.6 \pm 0.6$ \\
$\mathrm{Sb}$ & $765 \pm 40$ & $0.7 \pm 0.2$ & $1.4 \pm 0.1$ \\
\hline
\end{tabular}

cementation product. To the filtered solution, $0.8 \mathrm{~g} / \mathrm{L}$ of antimony and $0.4 \mathrm{~g} / \mathrm{L}$ copper were added to the solution as well as $2 \mathrm{~g} / \mathrm{L}$ of zinc dust.
Batch addition of the activators resulted in removal of metals summarized in Table 6 for a two-step batch process at $20{ }^{\circ} \mathrm{C}$ and Table 7 at $40{ }^{\circ} \mathrm{C}$. Batch cementation resulted 
Table 6 Concentration of metals in MOV leachate before and after batch additions of activators under optimized cementation conditions for $20{ }^{\circ} \mathrm{C}$

\begin{tabular}{llllll}
\hline Metal & Batch 1 & & Batch 2 & \multicolumn{1}{c}{$\begin{array}{l}\% \\
\text { change }\end{array}$} \\
\cline { 2 - 3 } $\begin{array}{l}\text { Pre-cementation } \\
\text { concentration }(\mathrm{mg} / \mathrm{L})\end{array}$ & $\begin{array}{l}\text { Post-cementation } \\
\text { concentration }(\mathrm{mg} / \mathrm{L})\end{array}$ & & $\begin{array}{l}\text { Pre-cementation } \\
\text { concentration }(\mathrm{mg} / \mathrm{L})\end{array}$ & $\begin{array}{l}\text { Post-cementation } \\
\text { concentration }(\mathrm{mg} / \mathrm{L})\end{array}$ \\
\hline $\mathrm{Co}$ & $443 \pm 10$ & $183 \pm 8.2$ & $181 \pm 8.0$ & $36.9 \pm 4.4$ \\
$\mathrm{Cu}$ & $407 \pm 41$ & $0.7 \pm 1.4$ & $402 \pm 37$ & $0.0 \pm 0.9$ \\
$\mathrm{Mn}$ & $59.9 \pm 1.0$ & $53.8 \pm 1.0$ & $53.3 \pm 0.8$ & $50.3 \pm 0.1$ & $0.1 \pm 0.4$ \\
$\mathrm{Ni}$ & $104 \pm 6.3$ & $16.2 \pm 2.3$ & $16.0 \pm 2.2$ & $1.2 \pm 0.7$ \\
$\mathrm{Sb}$ & $807 \pm 4.8$ & $4.6 \pm 2.5$ & $781 \pm 32$ & 100 \\
\hline
\end{tabular}

Table 7 Concentration of metals in MOV leachate before and after batch additions of activators under optimized cementation conditions for $40{ }^{\circ} \mathrm{C}$

\begin{tabular}{|c|c|c|c|c|c|}
\hline \multirow[t]{2}{*}{ Metal } & \multicolumn{2}{|l|}{ Batch 1} & \multicolumn{2}{|l|}{ Batch 2} & \multirow{2}{*}{$\begin{array}{l}\% \\
\text { change }\end{array}$} \\
\hline & $\begin{array}{l}\text { Pre-cementation } \\
\text { concentration }(\mathrm{mg} / \mathrm{L})\end{array}$ & $\begin{array}{l}\text { Post-cementation } \\
\text { concentration }(\mathrm{mg} / \mathrm{L})\end{array}$ & $\begin{array}{l}\text { Pre-cementation } \\
\text { concentration }(\mathrm{mg} / \mathrm{L})\end{array}$ & $\begin{array}{l}\text { Post-cementation } \\
\text { concentration }(\mathrm{mg} / \mathrm{L})\end{array}$ & \\
\hline $\mathrm{Co}$ & $414 \pm 1.0$ & $200 \pm 7.0$ & $194 \pm 6.4$ & $8.6 \pm 0.7$ & 98 \\
\hline $\mathrm{Cu}$ & $381 \pm 0.3$ & $4.6 \pm 0.8$ & $389 \pm 1.0$ & $0.0 \pm 0.6$ & 100 \\
\hline Mn & $59.3 \pm 1.0$ & $60.3 \pm 0.1$ & $58.4 \pm 0.2$ & $61.4 \pm 1.6$ & 3.6 \\
\hline $\mathrm{Ni}$ & $97.4 \pm 2.5$ & $13.2 \pm 1.3$ & $12.9 \pm 1.1$ & $0.0 \pm 0.4$ & 100 \\
\hline $\mathrm{Sb}$ & $759 \pm 4.8$ & $8.9 \pm 0.1$ & $772 \pm 15$ & $1.6 \pm 1.7$ & 100 \\
\hline
\end{tabular}

in complete removal of the copper and antimony activator along with all nickel and $92 \%$ of the cobalt from the MOV leachate at $20{ }^{\circ} \mathrm{C}$, while at $40{ }^{\circ} \mathrm{C}, 98 \%$ of cobalt was removed. The remaining cobalt could be removed by adding a third cementation step or increasing the temperature.

\section{Summary and Conclusions}

The aim of the study was to investigate if cementation could be used to produce a purified zinc electrolyte from sulfuric acid leaching of MOVs. This process, leaching then purification, would create a process suitable for recycling the zinc from the MOV. The leachate contained impurities of cobalt $(\sim 400 \mathrm{mg} / \mathrm{L})$ and nickel $(\sim 100 \mathrm{mg}$ / L) which needed to be removed to make the leaching solution suitable for zinc electrowinning.

The present investigation focused on solutions mainly at room temperature. From the information gathered, we can see that increasing the temperature does not significantly increase the amount of cobalt and nickel cemented from solution but mainly increases the cementation kinetics. At temperature above $40{ }^{\circ} \mathrm{C}$, Co was redissolved into the sample lowering the removal efficiency. It was seen that adjusting the $\mathrm{pH}$ of the cementation had the largest influence on the amount of impurities cemented from solution with $\mathrm{pH} 5.0$ being the most effective. At $\mathrm{pH}$, $52 \%$ of cobalt and $74 \%$ of nickel were removed from the MOV leachate. If the $\mathrm{pH}$ was greater than 5 , the kinetics of cementation was slower.

From the results obtained by studying different cementation parameters, an optimized study was done at 20 and $40{ }^{\circ} \mathrm{C}$. The optimized conditions were $0.4 \mathrm{~g} / \mathrm{L}$ copper, $0.8 \mathrm{~g} / \mathrm{L}$ antimony, $2 \mathrm{~g} / \mathrm{L}$ zinc dust, and a solution $\mathrm{pH}$ of 5 . Results showed that $56 \%$ of cobalt and $90 \%$ of nickel could be removed using these optimized condition. To further improve the amount of cobalt cemented from solution, higher temperatures $\left(\sim 60^{\circ} \mathrm{C}\right)$ could be used.

A study on the effect of a two-step batch addition of zinc dust was done to see if the amount of cobalt and nickel removed from solution can be improved. This investigation has shown that it is possible to purify the MOV leachate of $98 \%$ cobalt and all nickel using cementation. However, the economics of this method were not investigated but are important if this method it to be used to recycle zinc from the MOVs.

This research shows that zinc can be successfully recycled from discarded MOV by leaching pulverized MOV's. Cementation can be used to purify the leaching solution followed by electrolysis to recover metallic zinc. 
Acknowledgments The authors of this work would like to thank Chalmers Area of Advance Production for providing funding.

Open Access This article is distributed under the terms of the Creative Commons Attribution 4.0 International License (http://crea tivecommons.org/licenses/by/4.0/), which permits unrestricted use, distribution, and reproduction in any medium, provided you give appropriate credit to the original author(s) and the source, provide a link to the Creative Commons license, and indicate if changes were made.

\section{References}

1. Brundtland G et al (1987) Our common future ('Brundtland report'). Oxford University Press, Oxford

2. Report on critical raw materials for the EU, in Report of the Ad hoc Working Group on defining critical raw materials. 2014, European Commission. http://ec.europa.eu/growth/sectors/rawmaterials/specific-interest/critical/index_en.htm

3. Hultgren H (2014) Varistor material information. Personal Communication

4. ABB (2014) High voltage surge arresters, Buyer's Guide, ABB high voltage products surge arrestors. Ludvika, Sweden

5. Bernik S, Maček S, Bui A (2004) The characteristics of ZnO$\mathrm{Bi}_{2} \mathrm{O}_{3}$-based varistor ceramics doped with $\mathrm{Y}_{2} \mathrm{O}_{3}$ and varying amounts of $\mathrm{Sb}_{2} \mathrm{O}_{3}$. J Eur Ceram Soc 24(6):1195-1198

6. Gutknecht $\mathrm{T}$ et al (2015) Investigations into recycling zinc from used metal oxide varistors via $\mathrm{pH}$ selective leaching: characterization, leaching, and residue analysis. Sci World J 2015:11

7. Huang YQ et al (2001) Preparation and properties of ZnO-based ceramic films for low-voltage varistors by novel sol-gel process. Mater Sci Eng, B 86(3):232-236

8. Gordon RB et al (2003) The characterization of technological zinc cycles. Resour Conserv Recycl 39(2):107-135

9. Raghavan R, Mohanan PK, Verma SK (1999) Modified zinc sulphate solution purification technique to obtain low levels of cobalt for the zinc electrowinning process. Hydrometallurgy 51(2):187-206

10. Singh V (1996) Technological innovation in the zinc electrolyte purification process of a hydrometallurgical zinc plant through reduction in zinc dust consumption. Hydrometallurgy 40(1-2):247-262

11. Fosnacht DR, O'Keefe TJ (1983-12) The effects of certain impurities and their interactions on zinc electrowinning. Metall Trans B 14(4): 645-655

12. Tozawa K et al (1992) Comparison between purification processes for zinc leach solutions with arsenic and antimony trioxides. Hydrometallurgy 30(1-3):445-461
13. Nelson A et al (2000) The removal of cobalt from zinc electrolyte by cementation: a critical review. Miner Process Extr Metall Rev 20(4-6):325-356

14. Fontana A, Winand R (1971) In: Metallurgie XI, pp 162-168

15. de Blander F, Winand R (1975) Influence de l'antimoine et du cuivre sur la cementation du cobalt par le zinc. Electrochim Acta 20(11):839-852

16. Kroleva V (1980) Metallurgiya Sofia

17. van der Pas V, Dreisinger DB (1996) A fundamental study of cobalt cementation by zinc dust in the presence of copper and antimony additives. Hydrometallurgy 43(1-3): 187-205

18. Boyano B, Konareva V, Kolev N (2004) Removal of cobalt and nickel from zinc sulphate using activated cementation. J Min Metall Sect B 40(1):41-55

19. Dreher TM et al (2001) The kinetics of cobalt removal by cementation from an industrial zinc electrolyte in the presence of $\mathrm{Cu}, \mathrm{Cd}, \mathrm{Pb}, \mathrm{Sb}$ and $\mathrm{Sn}$ additives. Hydrometallurgy 60(2):105-116

20. BØrve K, Østvold T (1994) Norzink removal of cobalt from zinc sulphate electrolytes. In: Hydrometallurgy'94. Springer, Dordrecht, pp 563-577

21. Boyanov BS, Konareva VV, Kolev NK (2004) Purification of zinc sulfate solutions from cobalt and nickel through activated cementation. Hydrometallurgy 73(1-2):163-168

22. Joint Committee of Powder Diffraction Standards, in JCPDSICCD 2010. Philadelphia, USA

23. Sekula R, Wnek M, Slupek S (1999) Potential utilization method of scrap ceramic insulators. J Solid Waste Technol Manag 26(2):6

24. Olsson $\mathrm{E}$ (1988) Interfacial microstructure in $\mathrm{ZnO}$ varistor materials. In: Physics. Chalmers University of Technology, Göteborg, p 50

25. Jun D, De-quan W, Lan J, Man J (2002) Removal of cobalt from zinc sulphate solution using rude antimony trioxide as additive. Trans Nonferrous Met Soc 12(6):1172-1175

26. Krause B, Sandenbergh RF (2015) Optimization of cobalt removal from an aqueous sulfate zinc leach solution for zinc electrowinning. Hydrometallurgy 155:132-140

27. Lew R (1994) The removal of cobalt from zinc sulphate electrolytes using the copper-antimoney process. In: Materials engineering. The University of British Columbia, Vancouver

28. Yang D et al (2006) Mechanism of cobalt removal from zinc sulfate solutions in the presence of cadmium. Hydrometallurgy 81(1):62-66

29. Bøckman O, Østvold T (2000) Products formed during cobalt cementation on zinc in zinc sulfate electrolytes. Hydrometallurgy 54(2-3):65-78 